\title{
ADSORPTION OF MALACHITE GREEN ONTO STYRENE-METHACRYLATE BASED MOLECULARLY IMPRINTED POLYMER
}

\author{
Awokoya, K. N. ${ }^{1 *}$, Oninla, V. O. ${ }^{1}$, Babalola, J. O. ${ }^{2}$, Mbaeyi, N. N. ${ }^{1}$, Folorunso, F. T. ${ }^{1}$, \\ Ndukwe, N. A. ${ }^{3}$ \\ ${ }^{1}$ Department of Chemistry, Obafemi Awolowo University, Ile-Ife, Osun State, Nigeria \\ ${ }^{2}$ Biophysical Chemistry Unit, Department of Chemistry, University of Ibadan, Ibadan, Oyo State, Nigeria \\ ${ }^{3}$ Department of Chemical Sciences, Mountain Top University, Makogi, Ogun State, Nigeria \\ *Corresponding author: knawokoya@gmail.com, aawokoya75@gmail.com; +234803 4199393 \\ (Received: 25th July, 2019; Accepted: 3rd September, 2019)
}

\section{ABSTRACT}

\begin{abstract}
The adsorption of malachite green (MG) from aqueous medium by non-imprinted and molecularly imprinted styrene/methacrylate polymers was studied. The synthesized materials were characterized by powder X-ray diffraction, Fourier transform infra-red spectroscopy, scanning electron microscopy, and energy dispersive Xray spectroscopy. The effects of initial dye concentration, contact time and temperature on the adsorption capacity for malachite green were investigated and found to be about $200 \mathrm{~g} \mathrm{~kg}^{-1}$ for the imprinted polymer and 44 $\mathrm{g} \mathrm{kg}^{-1}$ for the non-imprinted polymer. The X-ray diffraction peaks at $2 \theta=18^{\circ}, 30^{\circ}$ and $42^{\circ}$ indicate the crystalline nature of the polymers. Uptake of malachite green increased with rise in contact time and concentration, for both polymers, while decrease in uptake was observed with rise in temperature. The kinetics of the adsorption of the dye on the imprinted polymer followed the pseudo-second order $\left(R^{2}=0.97\right)$, while that of the nonimprinted polymer followed the pseudo-first order $\left(R^{2}=0.87\right)$. Equilibrium study showed that the Freundlich isotherm better describes the adsorption of the dye on both polymers, indicating a multilayer adsorption. The values of $\Delta \mathrm{G}^{\circ}$ indicate the spontaneity and non-spontaneity of the dye removal by the imprinted and nonimprinted polymers respectively. The negative $\Delta \mathrm{H}^{\circ}$ and $\Delta \mathrm{S}^{\circ}$ for the imprinted polymer signify that the process is exothermic and occurred with decrease in the degree of randomness. Thus, the high quantity of MG adsorbed onto the imprinted polymer indicates the high potential of the use of the imprinting technology in the removal of toxic waste from water.
\end{abstract}

Keywords: Styrene-methacrylate, Imprinted polymer, Malachite green, Adsorption, Equilibrium

\section{INTRODUCTION}

Environmental pollution by synthetic dyes is an important issue in many countries especially when dumping is more economical than recycling (Vergis et al., 2018) due to insufficient legal regulations or controls. The estimated production of synthetic dyes is $7 \times 10^{5}$ to $1 \times 10^{6}$ tons per year worldwide. They are used in dyeing of textiles, paper, pulp, plastics, color photographs, foods, cosmetics and other industrial products (Ali and Gupta 2006; Rajeshkannan 2011; Khan et al., 2011; He et al., 2012; Ali et al., 2016). In the textile industries, approximately $50 \%$ of dyes is lost during the dyeing process and about 10 to $15 \%$ is discarded into environment as effluents (Yang et al., 2009) posing serious adverse effects on aquatic and human lives. Some dye compounds may even be carcinogenic or mutagenic (Umbuzeiro et al., 2005; Novotny et al., 2006; Mathur and Bhatnagar 2007; Tsuboy et al., 2007). Depending on the type of dyeing process and dyes used, the concentrations in textile effluents may vary from $10 \mathrm{mg} / \mathrm{L}$ to as high as $7000 \mathrm{mg} / \mathrm{L}$ (Koprivanac et al., 1993; Ghaly et al., 2014).

Basic dyes of high color intensity are mostly of the triphenylmethane class, an example being malachite green (MG). MG is water-soluble and is widely used as dye for paper, nylon and leather $(\mathrm{He}$ etal., 2012).

Methods that have been developed for costeffective dye removal include chemical oxidation, irradiation, coagulation-flocculation and precipitation, adsorption, combination of anaerobic and aerobic processes, membrane technologies, and ion exchange processes (Weber and Adams 1995; Wang et al., 2008; Parvin 2015; Zewail and Yousef 2015). Adsorption has been reported to be promising due to its efficiency, low cost and reusability of the sorbents (Ali et al., 2016; Khan et al., 2014a; Khan et al., 2014b; Khan et al., 2015; Khan and Nazir 2015; Khan et al., 
2018; Rahman 2016). However, as promising as these adsorbents are, many suffer from the limitations of non-selectivity and attrition. These can be overcome by the use of molecularly imprinted polymer (MIPs) (Awokoya et al., 2013). Adsorption on MIPs has been reported to be highly efficient, selective and robust. MIPs are reusable and are physically and chemically stable (Marty and Mauzac 2005; Awokoya et al., 2013). Other important advantages include long shelf life, low cost of production, applicability in harsh environment, and easy preparation (Zeng et al., 2012; Sharma et al., 2012).

Although MIPs have been reported since the 70s (Takagishi and Klotz 1972), MIP for dyes are comparatively recent and were initially reported in 2005 (Puoci et al., 2005). Amongst reported works, MIPs for dyes are mainly used as sorbents for solid phase extraction due to their high selectivity in complex samples (Zhu et al., 2009).

Therefore, the main aim of this work was to explore the use of styrene-methacrylate based imprinting material in the removal of MG from aqueous medium.

MG is an appropriate template on account of its $\pi-\pi$ interaction points with styrene to maintain stable functional monomer-template complexation. In addition, the attractive interactions between aromatic $\pi$ systems are one of the principal noncovalent forces governing supramolecular organization and recognition processes.

\section{MATERIALS AND METHODS Materials}

Styrene, ethyleneglycol dimethacrylate (EGDMA), MG, azobisisobutyronitrile (AIBN), methanol $(\mathrm{MeOH})$, and acetic acid were supplied by Sigma-Aldrich, Steinheim, Germany, and used as obtained. All chemicals used were of analytical grade.

\section{Preparation styrene-methacrylate based molecularly imprinted polymer}

Briefly, $0.822 \mathrm{mmol}(300 \mathrm{mg}$ ) MG was dissolved with $8.0 \mathrm{~mL}$ distilled water in a $100 \mathrm{~mL}$ standard flask, followed by the addition of $87.4 \mathrm{mmol}$ (10
$\mathrm{mL})$ styrene. Afterwards, $238.4 \mathrm{mmol}(45 \mathrm{~mL})$ EGDMA and $0.12 \mathrm{mmol}(30 \mathrm{mg})$ AIBN were added to the flask. The mixture was stirred until all the solids were dissolved. The flask was then placed on a heating module and polymerization was carried out at $70{ }^{\circ} \mathrm{C}$ for $35 \mathrm{~min}$. After polymerization, the flask was broken and the resulting hard green solid polymer was wiped free of the flask fragments and the monolith was ground with a mortar and pestle. As a control, a non-imprinted polymer (NIP) was also prepared, following the same procedure except that $\mathrm{MG}$ was omitted.

\section{Template removal}

The template was removed from the MIP as previously described (Awokoya et al. 2013) with minor modification. The MIP was exhaustively washed by magnetic stirring for $4 \mathrm{~h}$ with a mixture of $\mathrm{MeOH}$ and acetic acid (90:10, v/v) at room temperature. The mixture was centrifuged and the photometric absorbance at $617 \mathrm{~nm}$ of the supernatant liquid was determined with a UV-Vis spectrophotometer (UV-1800 Shimadzu, Kyoto, Japan). The washing process was repeated and continued until the absorbance of the filtrate at $617 \mathrm{~nm}$ was nil. Afterward, the MIP was washed for at least five times with $\mathrm{MeOH}$ to remove the acetic acid and facilitate drying.

\section{Characterization of MIP}

The functional groups of the polymers were characterized by Fourier transform infrared spectrophotometer (330 Nicolet Avatar FT-IR spectrometer, Shimadzu, Kyoto, Japan) in the range of $400-4000 \mathrm{~cm}^{-1}$. Images of the polymers were taken by scanning electron microscopy (SEM) (FEGSEM 6100 Zeiss ultra plus, Oberkochen, Germany), coupled with energy dispersive X-ray spectroscopy (EDS). The crystalline structures in the polymers were studied with powder X-ray diffraction (XRD) (Bruker D2, Phaser DOC-M88-EXX, 155 V4-07, 2010, Karlsruhe, Germany) using Cu tube with 1.5418 $(\AA)$ radiation. Data were recorded at a scan rate of $4^{\circ} /$ min over a $2 \theta$ range of $10^{\circ}-90^{\circ}$.

\section{Adsorption of MG onto MIP Concentration dependence study}

The adsorption of MG onto the polymers was 
performed in $100 \mathrm{~mL}$ plastic containers with lids in a thermostatic water bath at $27^{\circ} \mathrm{C}$ with speed controllable shaker (GFL, Burgwedel, Germany), $200 \mathrm{rpm}$. Amounts of $50 \mathrm{mg}$ each of leached MIP were added to $20 \mathrm{~mL}$ of MG solutions with initial concentrations of 10, 50, 100, 200, 400 and 500 $\mathrm{mg} / \mathrm{L}$. After shaking for $6 \mathrm{~h}$, the MIP was separated by centrifugation at $6000 \mathrm{rpm}$ for 10 $\mathrm{min}$, and the residual concentration of MG in the supernatant was determined photometrically at $617 \mathrm{~nm}$. The experiment was repeated using NIP in place of MIP. Each experiment was carried out in triplicate. The quantity of MG adsorbed, $\mathrm{q}_{\mathrm{e}}(\mathrm{g}$ $\mathrm{kg}^{-1}$ ), was calculated according to equation 1 :

$q_{\theta}=\frac{\left(C_{o}-C_{\theta}\right) V}{m}$

where $\mathrm{C}_{\mathrm{o}}\left(\mathrm{g} \mathrm{L}^{-1}\right)$ is the initial concentration of $\mathrm{MG}$, $\mathrm{C}_{\mathrm{e}}\left(\mathrm{g} \mathrm{L}^{-1}\right)$ is the concentration of $\mathrm{MG}$ in the solution after $6 \mathrm{~h} ; \mathrm{m}(\mathrm{kg})$ is the mass of MIP/NIP; and $\mathrm{V}(\mathrm{L})$ is the solution volume. The experimental data were fitted into the Langmuir (1918) and Freundlich (1906) isotherm models.

\section{Time dependence study}

Aliquots of $50 \mathrm{mg}$ adsorbent were added to $20 \mathrm{~mL}$ of an aqueous solution $100 \mathrm{mg} \mathrm{L}^{-1} \mathrm{MG}$ solution of MG and agitated for $6 \mathrm{~h}(0-360 \mathrm{~min})$. The adsorbent was separated by centrifugation at 6000 rpm for 10 min and the MG concentration in the supernatant was determined photometrically at $617 \mathrm{~nm}$. Data obtained were fitted to the pseudofirst order (Lagergren 1898; Ghorai et al. 2014) and pseudo-second order (Ho and McKay 1999) kinetic models.

\section{Thermodynamic study}

The thermodynamic behavior of the adsorption process was evaluated by performing the adsorption study at four different temperatures $\left(30,40,50,60^{\circ} \mathrm{C}\right)$. The study involved the use of $50 \mathrm{mg}$ adsorbent dose and the initial MG concentration of $100 \mathrm{mg} \mathrm{L}^{-1}$. The mixture was agitated for $6 \mathrm{~h}$.

\section{Selectivitystudy}

The selectivity of MIP-MG cavities was performed using two different dyes, commonly used in the industry. The dyes used in this study were methyl violet (MV) and methylene blue (MB). $50 \mathrm{mg}$ of MIP was mixed with $20 \mathrm{~mL}$ of $\mathrm{MV}$ and MB solutions with initial concentration of $500 \mathrm{mg} \mathrm{L}^{-1}$ at room temperature. The recognition coefficient $(\propto)$ of each dye to the polymer was compared to the rebinding of MG. This coefficient was used to evaluate the selectivity (Yang et al. 2005), and was calculated according to $\propto=\frac{[\hat{S}]_{(\text {imprinted })}}{[S]_{(\text {non-imprinted })}}$

Where $[\mathrm{S}]_{\text {(imprinted) }}$ represents the quantity of dye adsorbed onto the MIP $\left(\mathrm{g} \mathrm{kg}^{-1}\right)$ and $[\mathrm{S}]_{\text {(non-imprinted) }}$ is the quantity of dye adsorbed onto the NIP $\left(\mathrm{g} \mathrm{kg}^{-1}\right)$.

\section{RESULTS AND DISCUSSION Structural analysis of the MIP and NIP}

\section{Fourier Transform Infrared (FT-IR) Analyses}

FTIR spectroscopy is a useful tool for monitoring changes in chemical environments resulting from the addition or removal of functional groups in imprinted polymers (Cormack and Elorza 2004). The FT-IR spectra of leached (LMIP), unleached (UMIP) and control NIP materials within the range of 4000 to $450 \mathrm{~cm}^{-1}$ are shown in Fig. 1. LMIP, UMIP, and NIP spectra are similar because the materials have similar components, such as template, monomer, initiator and cross linker. Spectra with similar behavior have been reported by Abdallah et al., 2017). Analyses of these spectra $(1 \mathrm{a}, \mathrm{b}$ and $\mathrm{c})$ reveal the existence a typical $\mathrm{OH}$ bands of $\mathrm{H}_{2} \mathrm{O}$ at $3549,3535,3441,3437 \mathrm{~cm}^{-1}$ and $\mathrm{CH}$ vibrations at 2985, 2955, 1456, 1454, 1321 , $759,758 \mathrm{~cm}^{-1}$. In addition, the peaks at 2360 and $2359 \mathrm{~cm}^{-1}$ confirm the presence of $\mathrm{C} \equiv \mathrm{N}$ bonds of AIBN. The stretching band of $\mathrm{C}=\mathrm{O}$ at $1724 \mathrm{~cm}^{-1}$ affirms the structural characteristic of EGDMA (Zhang et al. 2017). All the spectra have a very strong and sharp peak at $1637 \mathrm{~cm}^{-1}$, which may be attributed to the existence of a large number of olefinic carbon-carbons $(\mathrm{C}=\mathrm{C})$ bonds of $\mathrm{MG}$, styrene and EGDMA (Wang et al. 2009; Khasanah et al. 2010). The presence of the above characteristic peaks suggests that polymerization process actually occurred. 


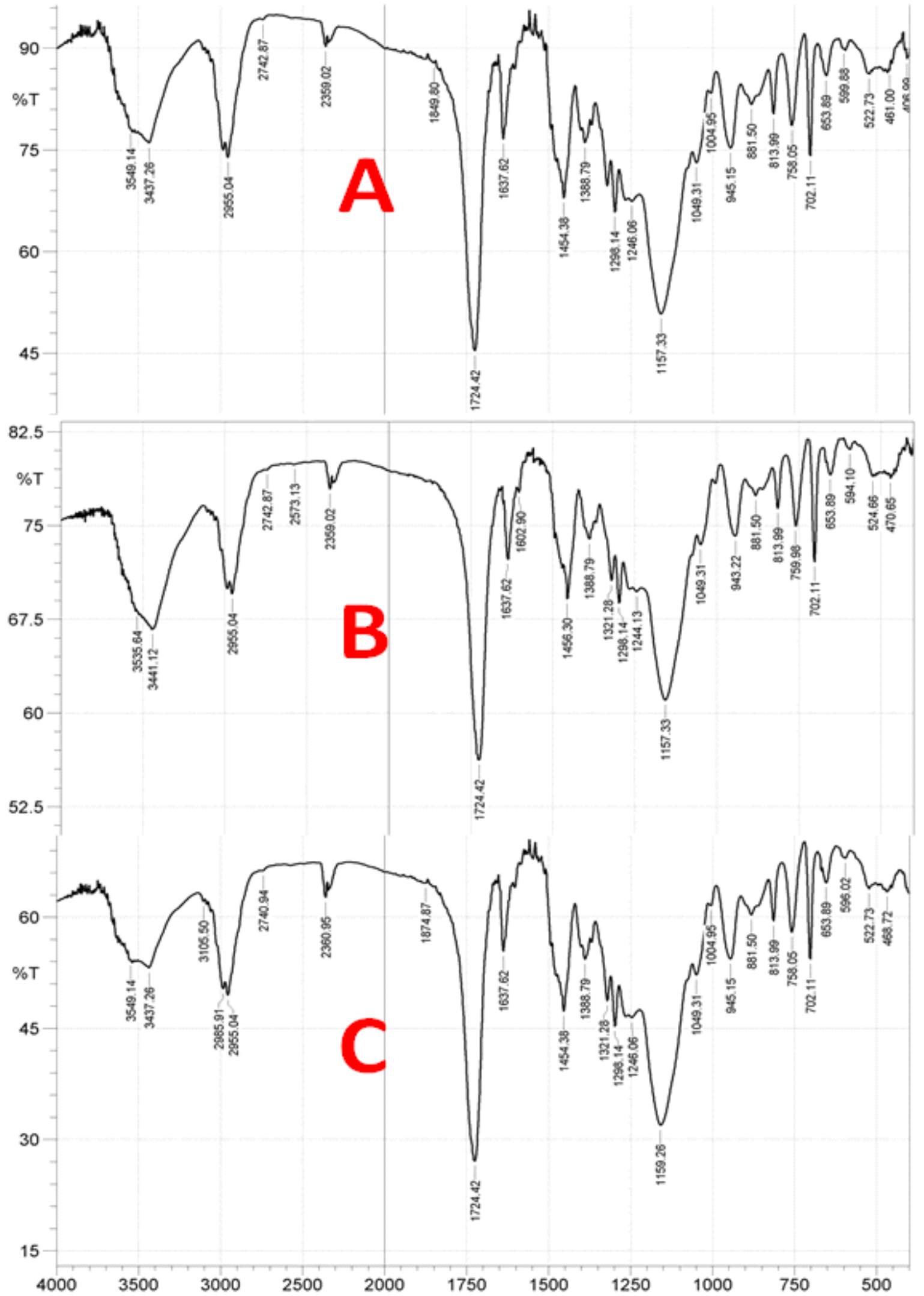

Fig. 1: FT-IR spectra of polymer particles: (A) leached MIP (B) unleached MIP (C) control NIP 


\section{SEM and EDS}

Surface morphology properties play an important role in a number of applications where both natural and synthetic polymeric materials are utilized. The surface morphology of the LMIP, UMIP and NIP were investigated by SEM. The main goal was to evaluate the physical appearance and internal structure of the polymer particles. As shown in Fig. 2A, the surface morphology of the leached polymer was relatively smooth compared to its unleached and non-imprinted counterparts (Figs. 2B and 2C). This phenomenon could be principally attributed to the removal of template molecule from the polymer matrix, as reported by Ji et al. (2008). The EDS spectra for all the polymers are shown in Figs. 2 ( $a, b$ and $c)$. The EDS spectrum of UMIP (Fig. 2b) showed the presence $\mathrm{Cl}$ atom, suggesting that the polymer network was formed with MG template molecule embedded in the inner matrix of the polymer. However, no trace of $\mathrm{Cl}$ atom was detected in the spectra of LMIP and NIP (Figs. 2a and 2c). The absence of $\mathrm{Cl}$ atom from the LMIP indicates a successful removal of MG from the polymer, hence the similarity between the two polymers.

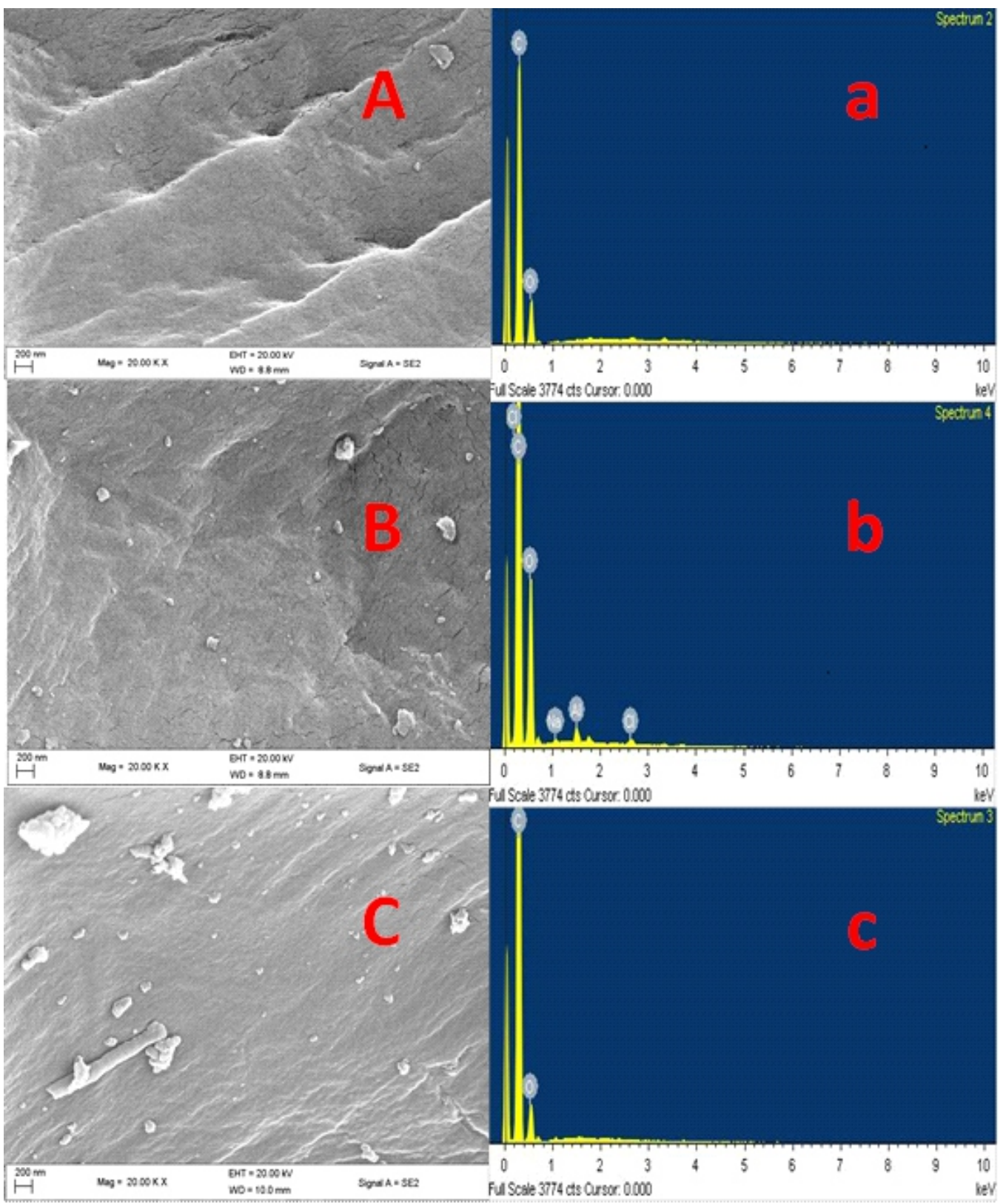

Fig. 2: Scanning electron micrographs and energy dispersive spectra of the polymers. A and a: LMIP, B and b: UMIP, C and c: NIP. 


\section{$X$-ray Diffraction}

XRD analysis (Chauhan and Chauhan 2017) was performed to check if the removal and noninclusion of the template disrupted the crystalline orientation of the polymer materials. The XRD patterns of the LMIP, UMIP and NIP are shown in Fig. 3. The distinct three characteristic diffraction peaks around $2 \theta=18^{\circ}, 30^{\circ}$ and $42^{\circ}$ were observed for all the polymers. The diffraction peak positions were unaltered after removal of the template (LMIP), which indicate that the crystalline structure of the unleached MIP was substantially maintained. This is basically consistent with the work by Qi et al. (2016). Moreover, the additional diffraction peak with $2 \theta$ $=10^{\circ}$ observed in the unleached MIP was assigned to MG, which is in agreement with the FT-IR spectra and thus is a confirmation that the MG template was successfully imprinted.

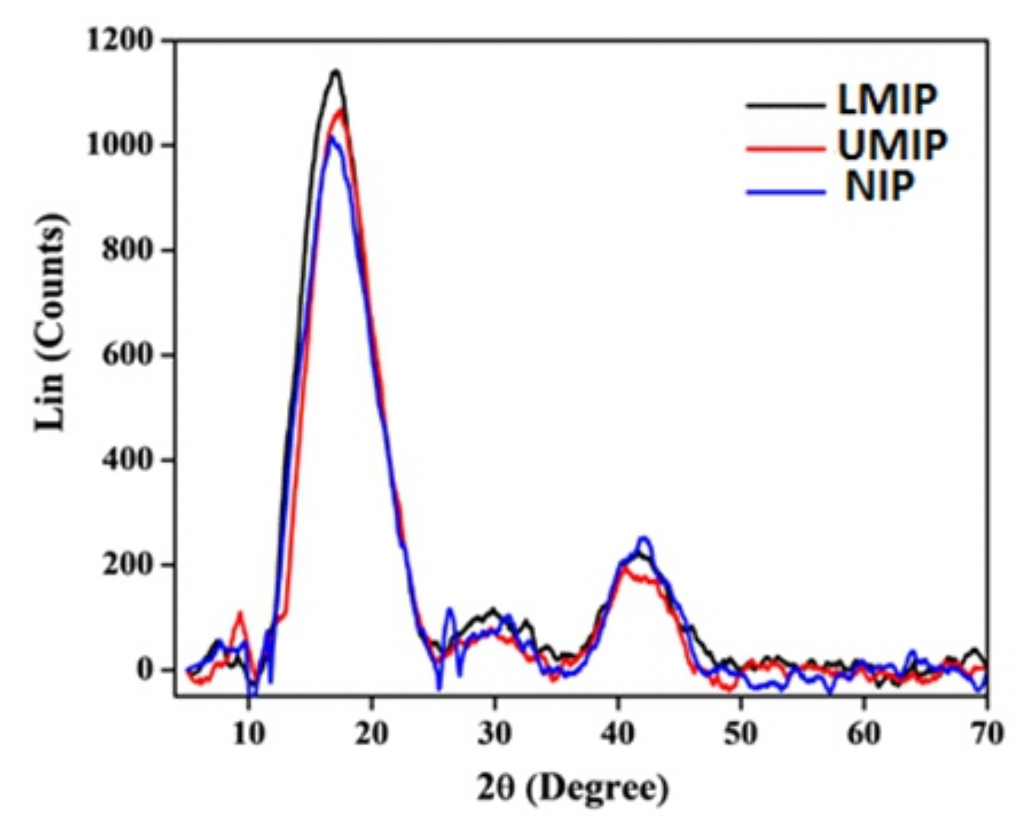

Fig. 3: X-ray diffraction patterns of leached MIP, unleached MIP and NIP.

\section{Quantitative assessment Effect of contact time}

Figure 4 shows the time dependent adsorption of MG onto MIP and NIP at $27^{\circ} \mathrm{C}$. The results showed a steady rise in MG uptake by the MIP, with increase in contact time from 0 to $240 \mathrm{~min}$, followed by a moderate rise in uptake up to 360 min. Equilibrium MG uptake was, however, not reached after the maximum time of $360 \mathrm{~min}$ considered. At the initial stage, especially within the first $60 \mathrm{~min}$, uptake of the dye was rapid, possibly due to the exposure of most of the binding sites on the MIP. Similar results have been reported in literature for adsorption of crystal violet onto alkali-modified rice husk by Chakraborty et al. (2011). Broadly speaking, dye adsorption consists of two phases: a very swift initial sorption, followed by a long period of much slower uptake (Sun et al. 2008). Under the same conditions, the MIP exhibited much higher recognition than the control NIP, indicating that binding sites complementary to the template were not present in the latter. 


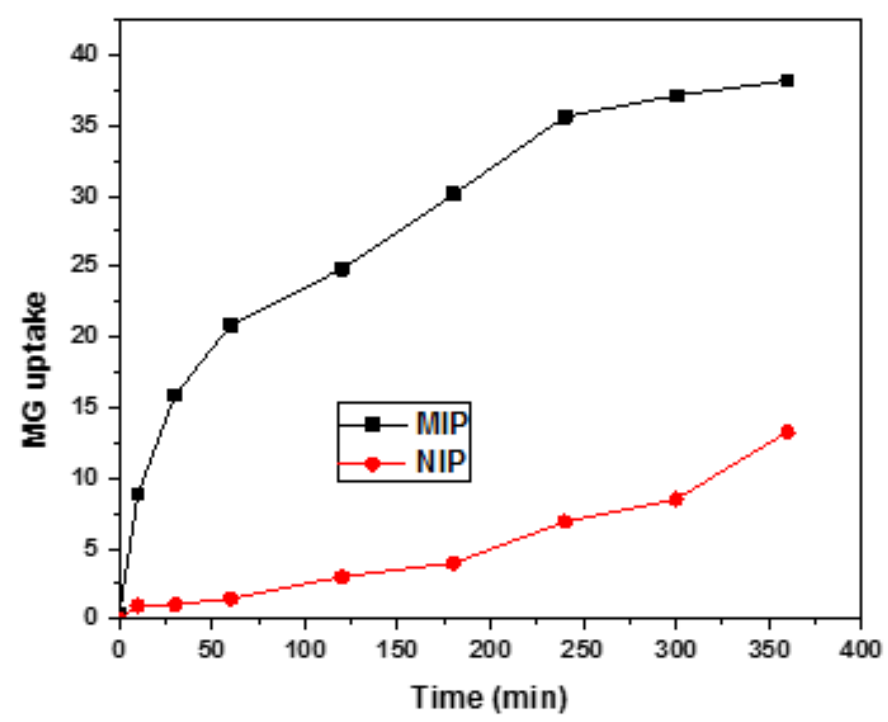

Fig. 4: Uptake of MG dye at different contact time

\section{Effect of initial adsorbate concentration}

The effect of the initial MG concentration on the dye adsorption capacity was investigated in the range $\left(10-500 \mathrm{mg} \mathrm{L}^{-1}\right)$ at room temperature. The initial adsorbate concentration factor depends on the instantaneous affinity between the dye concentration and the accessible binding sites on an adsorbent surface (Umoren et al. 2013). When the initial adsorbate concentrations were increased, uptake of MG by the MIP and NIP increased (Figure 5). This may be due to the increase in the driving force of the concentration activity (Chiou and Li 2002). The amount of MG adsorbed by both the MIP and NIP increased slightly when the adsorbate concentration was increased from 10 to $50 \mathrm{mg} \mathrm{L}^{-1}$. Afterwards, when the MG concentration was greater than $50 \mathrm{mg} / \mathrm{L}$, the quantity adsorbed increased significantly for the MIP, while NIP has relatively lower quantity adsorbed. Maximum adsorption capacity for MIP was about 4.47 times that of the NIP. The maximum adsorption capacities for MIP and NIP were $197 \mathrm{~g} \mathrm{~kg}^{-1}$ and $44 \mathrm{~g} \mathrm{~kg}^{-1}$ respectively. This indicates that the MIP has excellent specific surface active sites for MG molecule. In comparison with other adsorbents, such as rice straw (Gong et al. 2006), the synthesized MIP showed very high efficiency in the removal of $\mathrm{MG}$ from aqueous medium.

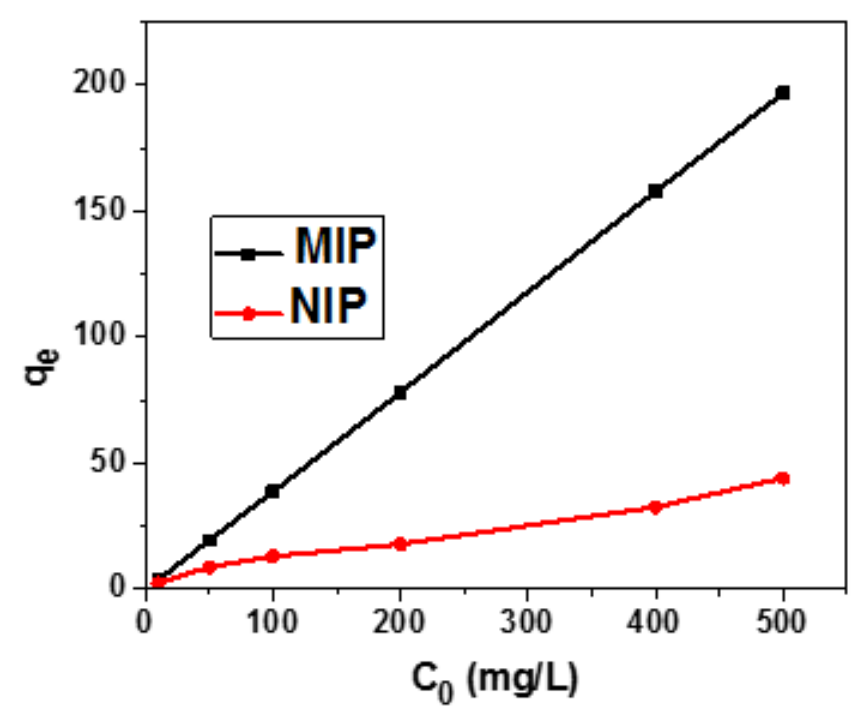

Fig. 5: Effect of initial adsorbate concentration on MG uptake by MIP/NIP 


\section{Effect of temperature and thermodynamic study}

The adsorption process is usually not operated at high temperature because of increase in operational cost (Sag and Kutsal 2000). The extents of MG molecule adsorption on the MIP and NIP at four different temperatures $\left(30^{\circ} \mathrm{C}, 40\right.$ ${ }^{\circ} \mathrm{C}, 50^{\circ} \mathrm{C}$ and $60{ }^{\circ} \mathrm{C}$ ) are shown in Figure $6 \mathrm{~b}$. Results indicate that when the temperature increased from $30^{\circ} \mathrm{C}$ to $60^{\circ} \mathrm{C}$, the amount of $\mathrm{MG}$ adsorbed onto MIP decreased from $38 \mathrm{~g} \mathrm{~kg}^{-1}$ to 37 $\mathrm{g} \mathrm{kg}^{-1}$ while that of the NIP decreased from $2.9 \mathrm{~g}$ $\mathrm{kg}^{-1}$ to $1.8 \mathrm{~g} \mathrm{~kg}^{-1}$. This suggests that higher temperature did not favor the adsorption process. The decrease in adsorption with increasing temperature, suggests weak adsorption interaction between MIP surface and the dye molecule, which supports physisorption process (Sag and Kutsal 2000; Vijayaraghavan and Yun 2006). Furthermore, other plausible reason for the reduction in the dye uptake by the MIP at higher temperature might be due to the fact that bonds in the cavities of the MIP were weakened and broken which facilitated weak adsorption interaction. Increase in temperature may also cause cavity expansion which may leads to leaching of $\mathrm{MG}$ adsorbed on the MIP (Uwah et al. 2013).

The thermodynamics of the adsorption process was determined by evaluating the thermodynamic parameters such as free energy change $\left(\ddot{\mathrm{A}} G^{\circ}\right)$, enthalpy change $\left(\ddot{\mathrm{A}} H^{\circ}\right)$, and entropy change $\left(\ddot{\mathrm{A}} S^{\circ}\right)$. The values of $\ddot{\mathrm{A}} S^{\circ}$ and $\ddot{\mathrm{A}} H^{\circ}$ for the adsorption process were determined from the intercept and slope of the plot of $\ln K_{c}$ versus $1 / \mathrm{T}$ (Figure 6a), using the van't Hoff equation. The negative $\underline{\ddot{A} G^{o}}$ values obtained for MIP at all temperatures $\left(-7.8,-7.5,-7.3\right.$ and $\left.-6.9 \mathrm{~kJ} \mathrm{~mol}^{-1}\right)$ indicate the feasibility as well as spontaneous nature of the adsorption of MG onto the polymers. On the other hand, $\ddot{\mathrm{A}} G^{\circ}$ values for the removal of MG by NIP (7.6, 5.5, 3.3 and $1.2 \mathrm{~kJ}$ $\mathrm{mol}^{-1}$ ) show non-spontaneity of the process. The negative values of $\ddot{A} G^{o}$ for the MIP decreased with increase in temperature, suggesting a steady decrease in the spontaneity of the process with rise in temperature. Bulut and Tez (2007) also reported a similar behavior for the removal of heavy metals from aqueous solution by sawdust. The $\ddot{A} G^{\circ}$ values for the MIP are between -20 $\mathrm{kJ} / \mathrm{mol}$ and $0 \mathrm{~kJ} / \mathrm{mol}$, indicating physical adsorption as the dominating mechanism in the adsorption process. The negative $\ddot{\mathrm{A}} \mathrm{H}^{\circ}(-15.9 \mathrm{~kJ}$ $\left.\mathrm{mol}^{-1}\right)$ and positive $\ddot{\mathrm{AS}}{ }^{\circ}\left(0.03 \mathrm{~kJ} \mathrm{~mol}^{-1}\right)$ values obtained for the MIP imply that the adsorption process was exothermic and occurred with decreased randomness at the solid/solution interface during the adsorption process (Nithya et al. 2017). The positive $\ddot{\mathrm{A}} \mathrm{H}^{\circ}$ value $\left(72.2 \mathrm{~kJ} \mathrm{~mol}^{-1}\right)$ obtained for the adsorption of MG onto NIP indicates that the adsorption process was endothermic, while the corresponding positive $\ddot{A} S^{\circ}$ value $\left(0.2 \mathrm{~kJ} \mathrm{~mol}^{-1}\right)$ signify that the freedom of MG is not too confined in the NIP, confirming a physical adsorption (Horsfall and Spiff 2005). 

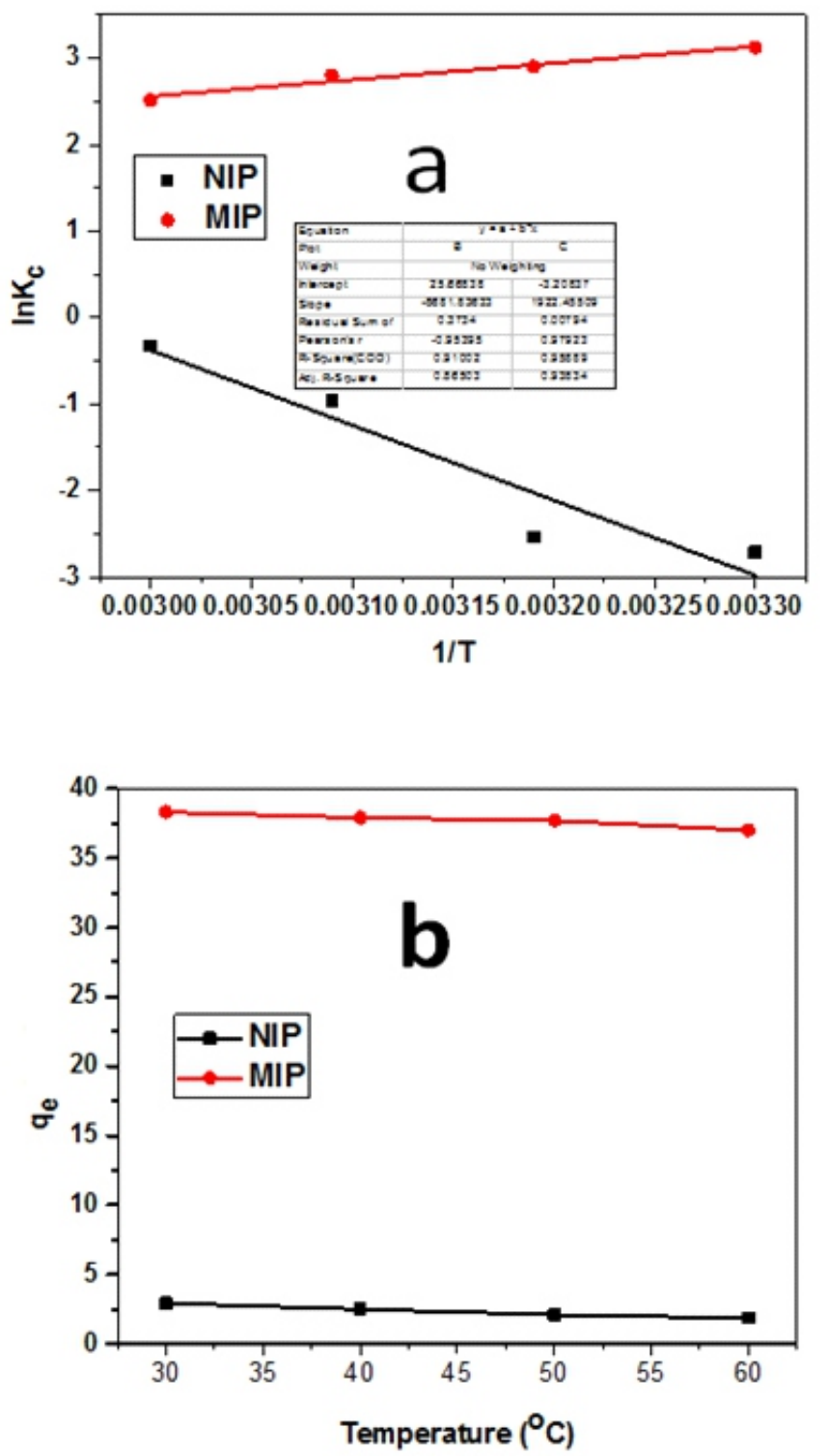

Fig. 6: Thermodynamic parameters plot (a) and effects of temperature (b) on adsorption of MG onto MIP and NIP.

\section{Modeling of the sorption process Kinetics of the adsorption process}

Kinetics of adsorption is an essential characteristic in determining the effectiveness of any adsorption process. It describes solute uptake rate, which in turn governs the residence time of the reaction (Hema and Arivolis 2008). In evaluating the kinetics of the adsorption of MG onto MIP and NIP, the pseudo-first-order (Lagergren 1898) and the pseudo-second-order (Ho and McKay 1999) kinetic models were used to fit the experimental data (Figures and Table not shown). The values of the correlation coefficient $\left(\mathrm{R}^{2}\right)$, indicate that the pseudo-second order model $\left(R^{2}=0.97\right)$ was better than the pseudo-first order model $\left(\mathrm{R}^{2}=0.61\right)$ in describing the adsorption of MG onto MIP. This assertion was also corroborated by the closeness of the calculated quantity of $\mathrm{MG}$ adsorbed ( $\mathrm{q}_{\mathrm{e} \text { (calc) }}=42.5 \mathrm{~g} \mathrm{~kg}^{-1}$ ) to the experimental value $\left(\mathrm{q}_{\mathrm{e}(\operatorname{expt})}=40.8 \mathrm{~g} \mathrm{~kg}^{-1}\right)$. It thus signifies that the adsorption rate was controlled by the concentration of MG in solution as well as the specific surface active sites on the MIP (Wang 2015). On the other hand, the $R^{2}$ value of 0.87 for the adsorption of MG by NIP shows that the kinetics of the process followed the pseudo-first order. This claim is also supported by the relatively large difference between the calculated $\mathrm{q}_{\mathrm{e}}$ value $\left(\mathrm{q}_{\mathrm{e}}\right.$ (calc) $\left.=25.7 \mathrm{~g} \mathrm{~kg}^{-1}\right)$ and experimental $\mathrm{q}_{\mathrm{e}}$ value $\left(\mathrm{q}_{\mathrm{e}(\text { expt) }}=\right.$ $19.8 \mathrm{~g} \mathrm{~kg}^{-1}$ ) determined for the removal of MG by 
NIP.

\section{Equilibrium modeling}

The interaction mechanism between adsorbate and adsorbent at equilibrium time is explored by Freundlich and Langmuir models (Benhamou et al. 2009; Parvini 2014). Modeling the adsorption isotherm data is an essential way for predicting and measuring the adsorption performance, which is critical for optimization of the adsorption mechanism pathways, expression of the adsorbents capacities, and effective design of the adsorption systems (Thompson et al. 2001).

The parameters and correlation coefficients obtained from the equilibrium modeling plots of both Langmuir and Freundlich are listed in Table 1. For both the MIP and NIP, the correlation coefficients of the Freundlich model were very close to unity (0.953 and 0.985$)$ and larger than the Langmuir model (0.757 and 0.847), thereby indicating that the adsorption of MG onto MIP and NIP occurred via a multiple layer process. The Freundlich constant, $\mathrm{K}_{f}$ obtained for the sorption of MG onto MIP was observed to be more than 5 fold that observed for NIP; indicating that the number of cavities with adequate geometry and good accessibility to the target analyte (MG) in MIP particles were higher than those in the NIP particles. This shows that the imprinting technology has made the polymer to be a better adsorbent for the target analyte.

Table 1: Parameters of Langmuir adsorption equation and Freundlich isothermal equation for adsorption experimental data.

\begin{tabular}{llcr}
\hline Isotherm & Parameters & Values (MIP) & Values (NIP) \\
\hline Langmuir & $\mathrm{Qm}\left(\mathrm{g} \mathrm{kg}^{-1}\right)$ & 943.39 & 52.938 \\
& $\mathrm{Ka}(\mathrm{mg} / \mathrm{L})$ & 0.397 & 0.006 \\
& $\mathrm{R}^{2}$ & 0.847 & 0.757 \\
Freundlich & $\mathrm{k} f$ & 6.669 & 1.239 \\
& $\mathrm{n}$ & 0.607 & 1.758 \\
& $\mathrm{R}^{2}$ & 0.953 & 0.985 \\
\hline
\end{tabular}

\section{Selectivity analysis of MIP for MG}

The specificity of the molecular recognition of different analytes by the MIP was evaluated by investigating the ability of the adsorbent to discriminate between two other analogue molecules, namely methyl violet (MV) and methylene blue (MB). Results showed that the MIP recognized and adsorbed MG better than MV and MB. The recognition coefficient for MG was 4.48, while the coefficients for MV and MB were 4.03 and 3.81, respectively. It is of interest to know that the adsorption of MG is relatively unaffected by other dyes with similar structures.

\section{CONCLUSIONS}

The ability of styrene-based imprinted polymer, synthesized by bulk polymerization, was found to be affected by operational parameters such as contact time, temperature and initial adsorbate concentration. The introduction and eventual leaching of MG template favored the formation of specific active sites in the imprinted material in the form of cavities complementary to MG. Compared with the NIP, the MIP matrix showed cavities responsible for its higher adsorption capacity. High maximum adsorption capacity recorded for MIP is an indication of it being a good adsorbent in the removal of MG. Kinetic data indicate that the rate determining step in the adsorption process is chemisorption. Equilibrium data indicate multilayer adsorption. Thermodynamic parameters indicate that the adsorption process was exothermic and spontaneous. Thus, the styrene-based MIP showed a very great potential in the removal of 
MG dye from aqueous medium, thereby suggesting the applicability of molecular imprinting technology in the removal pollutants from aqueous solution.

Acknowledgement: The authors would like to acknowledge and express their sincerest gratitude and indebtedness to the Department of Chemistry, Obafemi Awolowo University, Nigeria, for providing facilities in carrying out this research work.

Funding: This research did not receive any specific grant from funding agencies in the public, commercial, or not-for-profit sectors.

\section{REFERENCES}

Abdallah, N.A., Ibhrahim, H.F., \& Hegabe, N.H. (2017). Comparative Study of Molecularly Imprinted Polymer and Magnetic Molecularly Imprinted Nanoparticles as Recognition Sites for the Potentiometric Determination of Gemifloxacin Mesylate. International Journal of Electrochemical Science, 12, 10894-10910. doi: $10.20964 / 2017.11 .74$. www.electrochemsci.org.

Ali, I., Al-Othman, Z.A., \& Alwarthan, A. (2016). Molecular Uptake of Congo Red Dye from Water on Iron Composite Nano Particles. Journal of Molecular Liquids, $224, \quad 171-176 . \quad \mathrm{d}$ o i : 10.1016/j.molliq.2016.09.108.

Ali, I., \& Gupta, V.K. (2006). Advances in Water Treatment by Adsorption Technology. Nature Protocol, 1, 2661-2667. doi: 10.1038/nprot.2006.370.

Awokoya, K.N., Moronkola, B.A., Chigome, S., Ondigo, D.A., Tshentu, Z., \& Torto, N. (2013). Molecularly Imprinted Electrospun Nanofibers for Adsorption of $\mathrm{Nick}$ e $1-5,10,15,20$ Tetraphenylporphine (NTPP) in Organic Media. Journal of Polymer Research, 20, 148. doi: 10.1007/s10965-013-014-y.

Awokoya, K.N., Batlokwa, B.S, Moronkola, B.A., Chigome, S., Ondigo, D.A., Tshentu, Z., \& Torto, N. (2013). Development of a Styrene Based Molecularly Imprinted Polymer and Its Molecular Recognition Properties of Vanadyl
Tetraphenylporphyrin in Organic Media. International Journal of Polymeric Materials and Polymeric Biomaterials, $63, \quad 107-113 . \quad \mathrm{d}$ o i : 10.1080/00914037.2013.769255.

Benhamou, A., Baudu, M., Derriche, Z., \& Basly, J.P. (2009). Aqueous Heavy Metals Removal on Amine-Functionalized SiMCM-41 and Si-MCM-48. Journal of Hazardous Materials, 171, 1001-1008. doi.org/10.1016/j.jhazmat.2009.06.106.

Bulut, Y., \& Tez, Z. (2007). Removal of Heavy Metals from Aqueous Solution by Sawdust and Adsorption. Journal of Environmental Sciences, 19, 160-166.

Chakraborty, S., Chowdhury, S., \& Saha, P.D. (2011). Adsorption of Crystal Violet from Aqueous Solution onto $\mathrm{NaOH}-$ Modified Rice Husk. Carbohydrate Polymer, 86, $1533-1541$. d o i : 10.1016/j.carbpol.2011.06.058.

Chauhan, A., \& Chauhan, P. (2017). XRD: A Pioneer Technique for Characterizing the Polymer and Fiber. Journal of Textile Science E Engineering, 7, 303. doi: 10.4172/2165-8064.1000303.

Chiou, M.S., \& Li, H.Y. (2002). Equilibrium and Kinetic Modeling of Adsorption of Reactive Dye on Cross-Linked Chitosan Beads. Journal of Hazardous Materials, 93, 233-248. doi.org/10.1016/s03043894(02)00030-4.

Cormack, P.A.G., \& Elorza, A.Z. (2004). Molecularly Imprinted Polymers: Synthesis and Characterization. Journal of Chromatography B, 804, 173-182.

Freundlich, H.M.F. (1907). Über die Adsorption in Lösungen. Zeitschrift für Physikalische Chemie, 57, 385-471.

Ghaly, A., Ananthashankar, R., Alhattab, M., \& Ramakrishnan, V. (2014). Production, Characterization and Treatment of Textile Effluents: A Critical Review. Journal of Chemical Engineering $\&$ Process Technology, 5, 1-18. doi: 10.4172/21577048.1000182.

Ghorai, S., Sarkar, A., Raoufi, M., Panda, A.B., Schonherr, H., \& Pal, S. (2014). Enhanced Removal of Methylene Blue and Methyl Violet Dyes from Aqueous Solution Using 
a Nanocomposite of Hydrolyzed Polyacrylamide Grafted Xanthan Gum and Incorporated Nanosilica. ACS Applied Materials and Interfaces, 6, 47664777. doi: 10.1021/am4055657.

Gong, R., Jin, Y., Chen, F., Chen, J., \& Liu, Z. (2006). Enhanced Malachite Green Removal from Aqueous Solution by Citric Acid Modified Rice Straw. Journal of Hazardous Materials, 137, 865-870. doi: 10.1016/j.jhazmat.2006.03.010.

He, Y., Gao, J.F., Feng, F.Q., Liu, C., Peng, Y.Z., \& Wang, S.Y. (2012). The Comparative Study on the Rapid Decolorization of Azo, Anthraquinone and Triphenylmethane Dyes by Zero-Valent Iron. Chemical Engineering Journal, 179, 8-18. doi: 10.1016/j.cej.2011.05.107.

Hema, M., \& Arivolis, S. (2008). Adsorption Kinetics and Thermodynamics of Malachite Green unto Acid Activated Low Cost Carbon. Journal of Applied Sciences and Environmental Management, 12, 4351.

Ho, Y.S., \& G. McKay, G. (1999). Pseudo-Second Order Model for Sorption Processes. Process Biochemistry, 34, 451-465. doi.org/10.1016/S0032-9592(98)001125.

Horsfall, M., \& Spiff, A.I. (2005). Effects of Temperature on the Sorption of $\mathrm{Pb}^{2+}$ and $\mathrm{Cd}^{2+}$ from Aqueous Solution by Caladium bicolor (wild cocoyam) Biomass. Electronic Journal of Biotechnology, 8, 162-169. doi: 10.2225/vol8-issue2fulltext-4.

Ji, L., Saquing, C., Khan, S.A., \& Zhang, X. (2008). Preparation and Characterization of Silicon Nanoparticulate-Polyacrylonitrile Composite and Porous Nanofibers. Nanotechnology, 19, 085605.

Khan, T.A., Sharma, S., Khan, E.A \& Mukhlif, A.A. (2014a). Removal of Congo Red and Basic Violet 1 by Chir Pine (Pinus roxburghii) Sawdust, a Saw Mill Waste: Batch and Column Studies. Toxicological and Environmental Chemistry, 96, 555568. doi.org/10.1080/02772248.2014. 959017.

Khan, T.A., Rahman, R., Ali, I., Khan, E.A., \&
Mukhlif, A.A. (2014b). Removal of Malachite Green from Aqueous Solution Using Waste Pea Shells as Low-Cost Adsorbent - Adsorption Isotherms and Dynamics. Toxicological and Environmental Chemistry, 96, 569-578. doi.org/10.1080/02772248.2014.969268.

Khan, T.A., Nazir, M., Khan, E.A., \& Riaz, U. (2015). Multiwalled Carbon NanotubePolyurethane (MWCNT/PU) Composite Adsorbent for Safranin $\mathrm{T}$ and $\mathrm{Pb}$ (II) Removal from Aqueous Solution: Batch and Fixed-Bed Studies. Journal of Molecular Liquids, 212, 467-479. doi.org/10.1016/j.molliq.2015.09.036.

Khan, T.A., \& Nazir, M. (2015). Enhanced Adsorptive Removal of a Model Acid Dye Bromothymol Blue from Aqueous Solution Using Magnetic ChitosanBamboo Sawdust Composite: Batch and Column Studies. Environmental Progress and Sustainable Energy, 34, 1444-1454. doi.org/10.1002/ep.12147.

Khan, E.A., Shahjahan, \& Khan, T.A. (2018). Adsorption of Methyl Red on Activated Carbon Derived from Custard Apple (Annona squamosa) Fruit Shell: Equilibrium Isotherm and Kinetic Studies. Journal of Molecular Liquids, 249, 1195doi.org/10.1016/j.molliq.2017.11.125.

Khasanah, M., Mudasir, M., Kuncaka, A., Sugiharto, E., Supriyanto, G., \& Wafiroh, S. (2010). Enhancement of the Sensitivity and Selectivity of the Voltammetric Sensor for Uric acid Using Molecularly Imprinted Polymer. Indonesian Journal of Chemistry, 10, 295-300.

Koprivanac, N., Bosanac, G., Grabaric, Z., \& Papic, S. (1993). Treatment of Wastewaters from Dye Industry. Environmental Technology, 14, 385-390. doi.org/10.1080/09593339309385304.

Langmuir, I. (1918). The Adsorption of Gases on Plane Surface of Glass, Mica and Platinum. Journal of American Chemical Society, 40,1361 . doi: 10.1021/ja02242a004.

Lagergren, S. (1898). About the Theory of SoCalled Adsorption of Soluble Substances. 
Kungliga Svenska Vetenskapsakademiens Handlingar, 24, 1-39.

Marty, J.D., \& Mauzac, M. (2005). Molecular Imprinting: State of the Art and Perspective. Adv ances in Polymer Science, 172,1-25.

Mathur, N., \& Bhatnagar, P. (2007). Mutagenicity Assessment of Textile Dyes from Sanganer (Rajasthan). Journal of Environmental Biology, 28, 123-126.

Milonjic, S.K. (2007). A Consideration of the Correct Calculation of Thermodynamic Parameters of Adsorption. Journal of Serbian Chemical Society, 72, 1363-1367. doi: 10.2298/JSC0712363M.

Nithya, K., Sathish, A., Kumar, P.S., \& Ramachandran, T. (2017). Functional Group-assisted Green Synthesized Superparamagnetic Nanoparticles for the Rapid Removal of Hexavalent Chromium from Aqueous Solution. IET Nanobiotechnology, 11, 852-860. doi: 10.1049/iet-nbt.2016.0259.

Novotny, C., Dias, N., Kapanen, A., Malachova, K., Vandrovcova, M., Itavarra, M., \& Lima, N. (2006). Comparative Use of Bacterial, Algal and Protozoan Tests to Study Toxicity of Azo and Anthraquinone Dyes" Chemosphere, 63, 1436-1442. doi.org/10.1016/j.chemosphere.2005.10. 002.

Parvini, M. (2014). Equilibrium Studies in Adsorption of $\mathrm{Hg}$ (II) from Aqueous Solutions Using Biocompatible Polymeric Polypyrrole-Chitosan Nanocomposite. Polycyclic Aromatic Compounds, 34, $225-236 . \quad$ d o i : 10.1080/10406638.2014.886077.

Puoci, F., Garreffa, C., Iemma, F., Muzzalupo, R., Spizzirri, U.G \& Picci, N. (2005). Molecularly Imprinted Solid Phase Extraction for Detection of Sudan I in Food Matrices. Food Chemistry, 93, $349-353 . \quad$ d o i : 10.1016/j.foodchem.2004.11.014.

Qi, Y., Li, G., Wei, C., Zhao, L., \& Gong, B. (2016). Preparation of Magnetic Molecularly Imprinted Polymer for Melamine and Its Application in Milk Sample Analysis by HPLC. Journal of Biomedical Sciences, 5,
16. doi: 10.4172/2254-609X.100030.

Rahman, F. (2016) The Treatment of Industrial Effluents for the Discharge of Textile Dyes Using by Techniques and Adsorbents. Journal of Textile Science $\mathcal{E}$ Engineering, 6, 242. doi: 10.4172/21658064.1000242.

Rajeshkannan, R. (2011). Decolourization of Malachite Green Using Tamarind Seed: Optimization, Isotherm and Kinetic Studies. Chemical Industry and Chemical Engineering Quarterly, 17, 67-79. doi: 10.2298/CICEQ100716056R.

Sag, Y., \& Kutsal, T. (2000). Determination of the Biosorption Heats of Heavy Metal Ions on Zoogloea rumigera and Rhizopus arrbizus. Biochemical Engineering Journal, 6, 145-151. doi: 10.1016/s1369703x $(00) 00083-8$.

Sharma, P.S., D'Souza, F., \& Kutner, W. (2012). Molecular Imprinting for Selective Chemical Sensing of Hazardous Compounds and Drugs of Abuse. $\operatorname{Tr} A C$ Trends in Analytical Chemistry, 34, 59-77. doi: 10.1016/j.trac.2011.11.005.

Sun, X.F., Wang, S.G., Liu, X.W., Gong, W.X., Bao, N., \& Gao, B.Y. (2008). Competitive Biosorption of Zinc (II) and Cobalt (II) in Single - and Binary-Metal Systems by Aerobic Granules. Journal of Colloid and Interface Science, 324, 1-8. doi: 10.1016/j.jcis.2008.04.049.

Thompson, G., Swain, J., Kay, M., \& Forster, C.F. (2001). The Treatment of Pulp and Paper Mill Effluent: A review. Bioresource Tecbnology, 77, 275-286. doi.org/10.1016/s0960-8524(00)00060-2.

Takagishi, T., \& Klotz, I.M. (1972). Macromolecule-Small Molecule Interactions; Introduction of Additional Binding Sites in Polyethyleneimine by Disulfide Cross-Linkages. Biopolymers, $11, \quad 483-491$. doi.org/10.1002/bip.1972.360110213.

Tsuboy, M.S., Anjeli, J.P.F., Mantovani, M.S., Knasmüller, S., Umbuzeiro, G.A., \& Ribeiro, L.R. (2007). Genotoxic, Mutagenic and Cytotoxic Effects of the Commercial Dye Cl Disperse Blue 291 in the Human Hepatic Cell Line HepG2. 
Toxicology in Vitro, 21, 1650-1655. doi: 10.1016/j.tiv.2007.06.020.

Umbuzeiro, G.A., Freeman, H.S., Warren, S.H., Oliveira, D.P., Terao, Y., Watanabe, T., \& Claxton, D.L. (2005). The Contribution of Azo Dyes to the Mutagenic Activity of Cristais River. Chemosphere, 60, 55-64. doi: 10.1016/j.chemosphere.2004.11.100.

Umoren, S.A., Etim, U.J., \& Israel, A.U. (2013). Adsorption of Methylene Blue from Industrial Effluent Using Poly (vinyl alcohol). Journal of Materials $\mathcal{E}$ Environment Sciences, 4, 75-86.

Uwah, I.E., Ikeuba, A.I., Ugi, B.U., \& Udowo, V.M. (2013). Comparative Study of the Inhibition Effects of Alkaloid and Non Alkaloid Fractions of the Ethanolic Extracts of Costus Afer Stem on the Corrosion of Mild Steel In $5 \mathrm{M} \mathrm{HCl}$ Solution. Global Journal of Pure $\mathcal{E}$ Applied Sciences, 19, 23-32. doi.org/ 10.4314/gipas.v19i1.4.

Vergis, B.R., Hari Krishna, R., Kottam, N., Nagabhushana, B.M., Sharath, R., \& Darukaprasad, B. (2018). Removal of Malachite Green from Aqueous Solution by Magnetic $\mathrm{CuFe}_{2} \mathrm{O}_{4}$ Nano-Adsorbent Synthesized by One Pot Solution Combustion Method. Journal of Nanostructure in Chemistry, 8, 1-12. doi.org/10.1007/s40097-017-0249-y.

Vijayaraghavan, K., \& Yun, Y.S. (2006). Utilization of Fermentation Waste (Corynebacterium glutamicum) for Biosorption of Reactive Black Five from Aqueous Solution. Journal of Hazardous Materials, 41, 45-52. doi: 10.1016/j. jhazamat.2006.06.081.

Wang, J., Li, H., \& Yang, X. (2009). Preparation of Hollow Composite Spheres with Raspberry-Like Structure Based on Hydrogen-Bonding Interaction. Polymers for Advanced Technologies, 20, 965-971.

Wang, K.S., Chen, H.Y., Huang, L.C., Su, Y.C., \& Chang, S.H. (2008). Degradation of Reactive Black 5 Using Combined Electrochemical Degradation-Solar Light/Immobilized $\mathrm{TiO}_{2}$ Film Process and Toxicity Evaluation. Chemosphere, 72 , 299-305. doi: $10.1016 / \mathrm{j}$. chemosphere.2008.02.012.

Wang, T. (2015). Cu Doped $\mathrm{Fe}_{3} \mathrm{O}_{4}$ Magnetic Adsorbent for Arsenic: Synthesis, Property, and Sorption Application. RSC Advances, 62, 50011-50018. doi: 10.1039/C5RA03951G.

Weber, E.J., \& Adams, R.L. (1995). Chemical and Sediment Mediated Reduction of the Azo Dye Disperse blue 79. Environmental Science E Technology, 29, 1163-1170. doi: 10.1021/es00005a005.

Yang, X.Q., Zhao, X.X., Liu, C.Y., Zheng, Y., \& Qian, S.J. (2009). Decolorization of Azo, Triphenylmethane and Anthraquinone Dyes by a Newly Isolated Trametes sp. SQ01 and Its Laccase. Process Biochemistry, 44, 1185-1189. doi: 10.1016/j.procbio.2009.06.015.

Yang, K.G., Liu, Z.B., Mao, M., Zhang, X.H., \& Zhao, C.S. (2005). Molecularly Imprinted Polyether Sulfone Microspheres for the Binding and Recognition of Bisphenol. Analytica Chimica Acta, 546, 30-36. doi.org/10.1016/j.aca.2005.05.008.

Zeng, H., Wang, Y., Liu, X., Kong, J., \& Nie, C. (2012). Preparation of Molecular Imprinted Polymers Using Bi-Functional Monomer and Bicrosslinker for Solid Phase Extraction of Rutin. Talanta, 93, 172-181. doi: 10.1016/j.talanta. 2012.02.008.

Zewail, T.M., \& Yousef, N.S. (2015). Kinetic Study of Heavy Metal Ions Removal By Ion Exchange in Batch Conical Air Spouted Bed. Alexandria Engineering Journal, 54, 83-90. doi.org/10.1016/j.aej.2014. 11.008 .

Zhang, W., She, X., Wang, L., Fan, H., Zhou, Q., Huang, X., \& Tang, J.Z. (2017). Preparation, Characterization and Application of Molecularly Imprinted Polymer for Selective Recognition of Sulpiride. Materials, 10, 475. doi: 10.3390/ma10050475.

Zhu, Q., Wang, L., Wu, S., Joseph, W., Gu, X., \& Tang, J. (2009). Selectivity of Molecularly Imprinted Solid Phase Extraction for Sterol Compounds. Food Chemistry, 113, 608-615. doi.org/10.1016/j. foodchem.2008.07.044. 